\title{
Anti-tumour effects of all-trans retinoid acid 1 crasumat on serous ovarian cancer
}

\author{
Noor A. Lokmann ${ }^{1 \dagger}$, Rachel Ho ${ }^{1 \dagger}$, Kavyadharshini Gunasegaran' ${ }^{1}$, Wendy M. Bonner ${ }^{1}$, Martin K. Oehler ${ }^{1,2}$ and \\ Carmela Ricciardelli $i^{*}$ (D)
}

\begin{abstract}
Background: Annexin A2 is increased in serous ovarian cancer and plays an essential role in ovarian cancer invasion and metastasis. In combination with S100A10, annexin A2 plays an important role in the plasminogen activator system regulating plasmin production. The aim of this study was to investigate the potential utility of all-trans retinoid acid (ATRA), an inhibitor of the annexin A2-S100A10 signalling pathway, as a new therapeutic against serous ovarian cancer.
\end{abstract}

Methods: In this study we determined the effects of ATRA treatment (1-5 $\mu \mathrm{M})$ on annexin A2 and S100A10 expression, plasmin activation, and the ability of ATRA to inhibit serous ovarian cancer cell survival, motility and invasion in vitro. We also employed an ex vivo tissue explant assay to assess response to ATRA treatment in serous ovarian cancers. Cryopreserved serous ovarian cancer tissues were cultured on gelatin sponges for $72 \mathrm{~h}$ with ATRA $(1 \mu \mathrm{M})$. Effects on apoptosis and proliferation were assessed by immunohistochemistry using antibodies to cleaved caspase 3 or Ki67, respectively.

Results: Survival of serous ovarian cancer cells (OVCAR-3, OV-90, \& OAW28) was significantly decreased by ATRA treatment (1-5 $\mu \mathrm{M})$. ATRA $(1 \mu \mathrm{M})$ also significantly decreased proliferation (Ki67 positivity, $p=0.0034$ ), S100A10 protein levels $(p=0.0273$ ), and increased cell apoptosis (cleaved caspase-3 positivity, $p=0.0024$ ) in serous ovarian cancer tissues using the ex vivo tissue explant assay. In OAW28 cells, reduced cell survival following ATRA treatment was associated with a reduction of S100A10 mRNA and protein levels, S100A10 and annexin A2 membrane localization, plasmin generation, motility and invasion. In contrast, ATRA inhibited OV-90 cell survival and invasion but did not affect plasmin activation or S100A10 and annexin A2 expression or membrane localization.

Conclusions: These findings suggest that ATRA inhibits serous ovarian cancer proliferation and invasion via both S100A10 dependant and S100A10 independent mechanisms. Our results show that ATRA has promising potential as a novel therapy against serous ovarian cancer that warrants further evaluation.

Keywords: Serous ovarian cancer, Annexin A2, S100A10, All- trans retinoic acid

\section{Background}

Ovarian cancer is ranked the fifth leading causes of cancer death in women and is also the most lethal gynaecological malignancy in the developed world $[1,2]$. Despite improvements in surgery and systemic treatments, including a broad range of new chemotherapies and

\footnotetext{
* Correspondence: carmela.ricciardelli@adelaide.edu.au

${ }^{\dagger}$ Noor A. Lokman and Rachel Ho contributed equally to this work.

${ }^{1}$ Discipline of Obstetrics and Gynaecology, Adelaide Medical School,

Robinson Research Institute, University of Adelaide, Adelaide, South Australia

5000, Australia

Full list of author information is available at the end of the article
}

targeted therapies, the survival rate has not considerably changed over the last 20 years [2]. Up to $75 \%$ of women are diagnosed at advanced stage (stage III and IV) and it is projected that there will be approximately 22,440 new cases and 14,080 deaths due to ovarian cancer in 2017 in the United States [2]. Currently, the 5 year survival rate after diagnosis is only $29 \%$ at advanced stage, with $52 \%$ of the deaths occurring in women aged 60 years and above [2]. More effective molecularly targeted therapies to improve survival are therefore urgently required.

(c) The Author(s). 2019 Open Access This article is distributed under the terms of the Creative Commons Attribution 4.0 International License (http://creativecommons.org/licenses/by/4.0/), which permits unrestricted use, distribution, and 
Ovarian cancer has the predisposition to metastasize by invasion into mesothelium that lines the organs within the peritoneal cavity and mediate local invasion and metastasis to abdominal organs and structures such as the bowel and omentum [3-5]. To identify novel therapeutic targets involved in ovarian cancer metastasis, our laboratory investigated the interaction of ovarian cancer and peritoneal cells using proteomics $[6,7]$. Annexin A2 was identified by mass spectrometry to be up-regulated by ovarian cancer-peritoneal cell interactions $[8,9]$.

Annexin A2, a multi-functional phospholipid calciumbinding protein is involved in the plasminogen activation pathway $[7,8]$. Annexin A2 exists both as a monomer and a heterotetramer known as AIIt $[7,10]$. The annexin A2 monomer is an intracellular $38 \mathrm{kDa}$ protein, whilst the AIIt heterotetramer complex consisting of two subunits of annexin A2 monomers and two subunits of S100A10 (also known as p11) is localized on the plasma membrane $[7,11]$. There is emerging evidence showing an important role of the AIIt heterotetramer in the plasminogen activator system [7, 12-14]. The interaction between annexin A2, S100A10 and tissue plasminogen activator ( $\mathrm{t}-\mathrm{PA})$ mediates the conversion of plasminogen to plasmin which facilitates the extracellular matrix (ECM) degradation, matrix metalloproteinase (MMP) activation, epithelial to mesenchymal transition (EMT) and angiogenesis, leading to increased cancer cell migration and invasion $[8,15,16]$.

Our previous studies reported that annexin A2 plays an important role in ovarian cancer invasion and metastasis [8] and increased expression of both annexin A2 and S100A10 is associated with poor serous ovarian cancer outcome [9]. The aim of this study was to investigate an inhibitor of the annexin A2 signalling pathway, alltrans retinoid acid (ATRA), for its efficacy to inhibit serous ovarian cancer cell survival and invasion.

ATRA is an active vitamin A metabolite which is currently used as a primary treatment for patients with acute promyelocytic leukemia (APL) [17]. APL is a distinct subtype of acute myeloid leukemia that expresses the promyelocytic leukemia-retinoic acid receptor alpha (PML-RAR-alpha) oncoprotein and is characterized by severe bleeding resulting from increased plasmin production [17-20]. ATRA has been shown to be beneficial in inducing differentiation and promoting apoptosis of leukemic cells and improving bleeding symptoms by inhibiting plasmin production and decreasing expression of annexin A2 and S100A10 [21-23]. Due to its relatively low systemic toxicity there is a great interest in expanding the therapeutic use of ATRA in other cancer types [24-26].

While the effects of ATRA on ovarian cancer proliferation and apoptosis have been previously investigated
[27-31], to date no data has been reported on the effects of ATRA on both annexin A2 and S100A10 expression in serous ovarian cancer cells. This study evaluated the effects of ATRA on annexin A2 and S100A10 expression, plasmin activation, and the ability of ATRA to inhibit serous ovarian cancer cell survival and invasion. We also employed for the first time an ex vivo tissue explant assay to assess response to ATRA treatment in serous ovarian cancers.

\section{Methods \\ Cell culture}

Serous ovarian cancer cell lines COV362, COV318 and OAW28, were purchased from the European Collection of Cell culture (ECCC, Cell Bank Australia) in November 2014. OVCAR-3 were purchased from American Type Culture Collection (ATCC, VA, USA) in October 2016. OV-90 cells were obtained from ATCC in 2008 and authenticated by short tandem repeat (STR) DNA profile on 05/05/2016. COV362, COV318 and OAW28 cell lines were grown in DMEM medium (Life Technologies, Carlsbad, CA, USA) and supplemented with $10 \%$ foetal calf serum (FCS) (Sigma-Aldrich St Louis, MO, USA). OV-90 cell line was grown in RPMI 1640 medium supplemented with 10\% FCS whilst OVCAR-3 cell line was supplemented with 5\% FCS. All cell lines were cultured with antibiotics (100 U penicillin G, $100 \mu \mathrm{g} /$ $\mathrm{ml}$ streptomycin sulphate and $0.25 \mu \mathrm{g} / \mathrm{ml}$ amphotericin B, Sigma Aldrich) and maintained at $37^{\circ} \mathrm{C}$ in $5 \% \mathrm{CO}_{2}$ environment and routinely checked for mycoplasma contamination.

Primary ovarian cancer cells were derived from ascites collected from advanced stage serous ovarian cancer patients as described previously [32]. All primary cells were grown in advanced RPMI 1640 medium (cat no 12633020, Life Technologies) supplemented with $4 \mathrm{mM} \mathrm{L-glu-}$ tamine, 10\% FCS (Sigma Aldrich) and antibiotics (100 U penicillin G, $100 \mu \mathrm{g} / \mathrm{ml}$ streptomycin sulfate and $100 \mu \mathrm{g} /$ $\mathrm{ml}$ amphotericin B, Sigma Aldrich). The clinicopathological characteristics of the patients whose ascites was used to isolate the primary cells are shown in Additional file 1: Table S1.

\section{Cell survival assay}

Ovarian cancer cell lines (OVCAR-3, OAW28, COV318, COV-362, OV-90) and primary serous ovarian cancer cells ( $n=6$ patients) were plated at 5000 cells/well in a 96 well plate and treated in quadruplicates with ATRA (1 \& $5 \mu \mathrm{M})$ (R2625, Sigma-Aldrich) or control medium containing $0.1 \%$ DMSO. The medium was changed after 3 days with media containing either ATRA or $0.1 \%$ DMSO (solvent control). After 6 days treatment, conditioned media $(\mathrm{CM})$ was removed and 3-(4,5-dimethylthiazol-2-yl)-2,5-diphenyltetrazolium bromide (MTT) (5 mg/ 
$\mathrm{mL} \mathrm{1:10} \mathrm{at} \mathrm{respective} \mathrm{medium,} \mathrm{Sigma-Aldrich)} \mathrm{was} \mathrm{added}$ and cells were incubated for $4.5 \mathrm{~h}$ at $37{ }^{\circ} \mathrm{C}$. Following the addition of MTT solvent $(0.1 \mathrm{~N} \mathrm{HCl}$ in isopropanol), absorbance readings were measured at $595 \mathrm{~nm}$ using the Triad series multimode detector plate reader (Dynex technologies, VA, USA) as described previously [33].

\section{Plasmin activation assay}

Serous ovarian cancer cells (OAW28, OV-90 \& OVCAR3) were plated in 96 well plates (5000 cells/well) and treated with ATRA $(1-5 \mu \mathrm{M})$ for 6 days. Cells were washed with $0.1 \mathrm{M}$ phosphate buffered saline (PBS), $\mathrm{pH} 7.4$ and treated for $10 \mathrm{~min} \pm 0.5 \mu \mathrm{M}$ plasminogen (P7999, Sigma Aldrich) and in the presence or absence of plasmin inhibitor ( $\varepsilon$-aminocaproic acid; $\varepsilon$-ACA, 100 $\mathrm{mM}$, Sigma Aldrich) prior to the addition of the plasmin substrate, chromozyme PL (3 mM in $100 \mathrm{mM}$ glycine, Roche Diagnostics, Mannhein, Germany). Plasmin activity was measured at $405 \mathrm{~nm}$ using the Triad series multimode detector (Dynex Technologies, VA, USA) over a $2 \mathrm{~h}$ period as described previously [6]. The colorimetric change resulting in the formation of yellow $p$-nitroaniline is a direct measure of the plasmin activity. Plasmin (0.1 U/ml, P1867, Sigma Aldrich) was used as a positive control and negative controls included parallel wells containing no chromozyme PL substrate and growth media alone, which served as the reagent blank.

\section{Cell motility and invasion}

Ovarian cancer cell lines (OAW28 \& OV-90) were treated with ATRA (1 and $5 \mu \mathrm{M})$ for 6 days in $75 \mathrm{~cm}^{2}$ flasks. Cells were trypsinized, labelled with calcein-AM $(1 \mu \mathrm{g} / \mathrm{ml}$, Invitrogen $)$ and added on to uncoated $12 \mu \mathrm{m}$ filters inserts (96 well plate, Chemo Tx, Neuro Probe, MD, USA) for motility assays or $12 \mu \mathrm{m}$ filters coated with Geltrex $(0.6 \mu \mathrm{l} /$ well, Life Technologies) for invasion assays. FCS (10\%) was used as chemoattractant in the bottom chamber for both the motility and invasion assays. After $6 \mathrm{~h}$, cells that migrated or invaded into the lower chamber were measured. The fluorescence was measured at $485-520 \mathrm{~nm}$ using the Triad series multimode detector (Dynex Technologies, VA, USA) as previously described [8].

\section{RNA extraction and quantitative real-time PCR}

Ovarian cancer cell lines (OAW28, OV-90) were plated at 10-15,000 cells/well in a 96 well plate and treated in triplicate with ATRA $(0-5 \mu \mathrm{M})$ for 1-6 days. Total RNA was isolated and reverse transcribed using the TaqMan ${ }^{\circ}$ Gene expression Cells-to-CT ${ }^{\mathrm{Tm}}$ kit (Applied Biosystems, Mulgrave, Victoria, Australia), as per the manufacturer's instructions as described previously [32]. Resultant cDNA was stored as $50 \mu \mathrm{l}$ aliquots at $-20^{\circ} \mathrm{C}$ for
qRT-PCR analysis. qRT-PCR reactions were performed on cDNA samples using TaqMan ${ }^{\circ}$ primer sets for ANXA2 (Hs00743063_s1) and S100A10 (Hs00751478_s1) using the Quantstudio $12 \mathrm{~K}$ Flex Real Time PCR System (Applied Biosystems). PCR cycling conditions were as follows: $50^{\circ} \mathrm{C}$ for $2 \mathrm{~min}, 95^{\circ} \mathrm{C}$ for $10 \mathrm{~min}$ followed by $40 \mathrm{cy}$ cles of $95^{\circ} \mathrm{C}$ for $15 \mathrm{~s}$ and $60^{\circ} \mathrm{C}$ for $1 \mathrm{~min}$. CT values were normalised to the house keeping gene $\beta$-actin (4333762F, Applied Biosystems) using the $2^{-\Delta \Delta C T}$ method. $\beta$-actin $\mathrm{CT}$ values were not altered by ATRA treatment (data not shown).

\section{Western blotting}

Ovarian cancer cell lines (OAW28, OV-90) were treated with ATRA $(1,5 \mu \mathrm{M})$ for 6 days to $80 \%$ confluence in $75 \mathrm{~cm}^{2}$ flasks. Cells were dislodged using a cell scraper and cell pellet were resuspended in $200 \mu \mathrm{l}$ of RIPA buffer (1\% Nonidet P-40, $1 \%$ sodium deoxycholate, $0.1 \%$ SDS, $0.15 \mathrm{M}$ sodium chloride, $50 \mathrm{mM}$ Tris- $\mathrm{HCL}$ and $1 \mathrm{mM}$ EDTA, pH 8.0 with protease inhibitor) spun at 7000 $\mathrm{rpm}$ for $10 \mathrm{~min}$ and stored at $-20^{\circ} \mathrm{C}$. Equal amounts of protein were electrophoresed and transferred to PVDF membranes (GE Healthcare, Little Chalfont, Buckinghamshire, UK) as described previously [6]. Proteins bands were detected with mouse monoclonal antibodies to annexin A2 (1/2000, Clone 5, 610069, BD Biosciences, North Ryde, NSW, Australia) or S100A10 (1/ 2000, Clone 148, 610070, BD Biosciences), anti-mouse IgG peroxidase-conjugated secondary antibody $(1 / 4000$, A0168, Sigma Aldrich), enhanced chemiluminescence (GE Healthcare), and ChemiDoc ${ }^{\mathrm{rat}}$ MP Imaging System with ImageLab ${ }^{\text {th }}$ software (Bio-Rad, Hercules, CA, USA) [8]. $\beta$-actin, used as a loading control was detected using a rabbit polyclonal antibody to $\beta$-actin $(1 / 2000$, ab8227, Abcam, Cambridge, MA, USA) and anti-rabbit IgG peroxidase-conjugated secondary antibody $(1 / 4000$, AP132P, Merck, Millipore, Bayswater, VIC, Australia).

\section{Immunocytochemistry}

Ovarian cancer cells (OAW28 \& OV-90) were plated $(10,000-15,000$ cells/well) in 8 well tissue culture chamber slides (Nunclon ${ }^{\text {TM }}$ Lab-Tek II Chamber slide, RS Glass Slide, Naperville, IL) in $500 \mu \mathrm{l} 10 \%$ FCS RPMI for $24 \mathrm{~h}$ and treated with control medium $(0.1 \%$ DMSO) or ATRA $(5 \mu \mathrm{M})$. The medium was changed after 3 days treatment with either control medium or medium containing ATRA $(5 \mu \mathrm{M})$. After 6 days treatment, cells were washed with cold PBS $(3 \mathrm{x})$ and fixed with cold $100 \%$ methanol ( $3 \mathrm{~min}$ ) and cold $100 \%$ acetone (1 min), washed with PBS $(2 \times 5 \mathrm{~min})$, blocked with $5 \%$ goat serum and incubated overnight with mouse monoclonal annexin A2 (1/100, BD Biosciences) or S100A10 $(1 / 200$, BD Biosciences) antibodies. Annexin A2 or S100A10 was visualized with goat anti-mouse Alexa 
Fluor ${ }^{\circledR} 488$ or goat anti-mouse Alexa Fluor ${ }^{\circledR} 594$ for 1 h at RT, (1/200, Molecular Probes, Life Technologies) respectively, and slides were mounted with ProLong Gold Antifade Mountant with DAPI (P36931, Molecular Probes, Life Technologies). Cells were viewed with an epifluorescence microscope (BX50, Olympus, Tokyo, Japan) and imaged using a 40x objective and a Spot RT digital camera (Diagnostic Instruments, Sterling Heights, MI). Negative controls included mouse immunoglobulin or no primary antibody. The percentage of cells with membrane staining in control and ATRA treated cells were determined visually by an assessor that was blinded to the treatment groups. To calculate the $\%$ of positive cell with membrane staining, cells $(\sim 200-$ $300)$ in five high power images were scored visually for the presence or absence of annexin A2 or S100A10 membrane staining.

\section{Ex vivo tissue explant assay}

Cryopreserved serous ovarian tissues stored in liquid nitrogen $(n=12)$ were thawed, dissected into $1-\mathrm{mm}^{3}$ pieces, and explanted onto gelatine dental sponges (Spongostan, Johnson \& Johnson, Humanus Dental AB, Malmo, Sweden) immersed in RPMI-1640 media supplemented with 10\% FCS and antibiotics as described previously [34]. Tissue explants were incubated with control media $(0.1 \%$ DMSO) or ATRA $(1 \mu \mathrm{M})$ in a humidified atmosphere at $37^{\circ} \mathrm{C}$ containing $5 \% \mathrm{CO}_{2}$, collected and fixed with $10 \%$ formalin (Sigma-Aldrich) after $72 \mathrm{~h}$ treatment. The clinical and pathological characteristics of the patients used for explant culture are summarized in Additional file 2: Table S2.

\section{Immunohistochemistry}

Effects of ATRA on proliferation and apoptosis in explant tissues were assessed by immunohistochemistry as described previously [34]. Tissue sections were incubated over night at $4{ }^{\circ} \mathrm{C}$ with rabbit monoclonal antibody to Ki67 (1/400, M3060, Taylor Biomedical Pty Ltd., NSW, Australia) or rabbit polyclonal antibody to cleaved caspase 3 (1/200, $9661 \mathrm{~L}$, Cell Signalling). The following day, the slides were incubated with biotinylated goat anti-rabbit (1/400, E0432018 Dako, North Sydney, NSW, Australia) and streptavidin-HRP (1/500, P0397 Dako) for $1 \mathrm{~h}$ at room temperature. Diaminobenzidine $/ \mathrm{H}_{2} \mathrm{O}_{2}$ (Sigma Aldrich), substrate was used to detect immunoreactivity before counterstaining with $10 \%$ haematoxylin (Sigma Aldrich), dehydrating and mounting in Pertex (Medite Medizintechnik, Germany). Additional sections were immunostained with annexin A2 and S100A10 antibodies as described previously [9]. Slides were digitally scanned using the NanoZoomer (Hamamatsu Phontonics K.K, Hamamatsu, Japan). Up to 5-8 cancer tissue areas were randomly selected and cells positive for Ki67 and cleaved caspase 3 were counted by two independent assessors who were blinded to the treatment [34]. Total annexin A2 and S100A10 including membrane and cytoplasmic staining was measured by video image analysis (VideoPro 32; Leading Edge P/L, Marion, South Australia, Australia) as described previously [35]. Measurements of the diaminobenzidine (DAB) stained area (i.e. positively stained area in pixel units) and the total tumor area examined (i.e. positively and negatively stained area in pixel units) from 5 to 10 high power fields were used to derive the $\%$ positive area (\% POS).

\section{Statistical analysis}

All statistical analyses were performed using GraphPad Prism (version 7.02, CA, USA). The Student's t-test or one-way ANOVA was used to assess statistical significance between control and treatment groups (RT-PCR, MTT assay, motility and invasion assays). The Friedman pair test was used to assess differences between control and ATRA treatment groups in the MTT assay using the primary serous ovarian cancer cells. The Wilcoxon rank paired test was used to assess differences between control and ATRA treatment groups in the ex vivo explants assays. The null hypothesis is that ATRA treatment has no effect. Statistical significance was accepted at $p<$ 0.05 .

\section{Results}

\section{Effects of ATRA treatment on serous ovarian cancer cell survival}

Survival of OVCAR-3 (Fig. 1a), OAW28 (Fig. 1b) and OV-90 (Fig. 1e) cells was significantly reduced after 6 days of ATRA $(5 \mu \mathrm{M})$ treatment but no significant effects were observed on COV318 (Fig. 1c) or COV362 cells (Fig. 1d). The most sensitive cell lines were OV-90 (cell survival reduced to $78.6 \%$ of control with $5 \mu \mathrm{M}$ ATRA) and OVCAR-3 (78.8\% of control) followed by OAW28 (87.6\% of control). ATRA treatment $(5 \mu \mathrm{M})$ for 6 days also had a significant effect on the survival of the primary serous ovarian cancer cells $(n=6)$ isolated from patient's ascites (range 86.7-98\% of control, Fig. 1f, $p=0.0017$ ). Response to ATRA treatment in the ovarian cancer cell lines did not correlate with expression of ANXA2, S100A10 or retinoic acid receptor alpha (RARA) as all cell lines exhibited similar gene expression levels (Additional file 3: Figure S1a). Similarly there was no relationship between ATRA response and ratio of two genes CRABP2/FABP5, intracellular lipid binding proteins, previously shown to be associated with retinoic acid induced growth inhibition [36] (Additional file 3: Figure S1b). Three of the serous ovarian cancer cell lines (OVCAR-3, OAW28 and OV-90) that were growth-inhibited by ATRA treatment were selected and investigated in further studies below. 

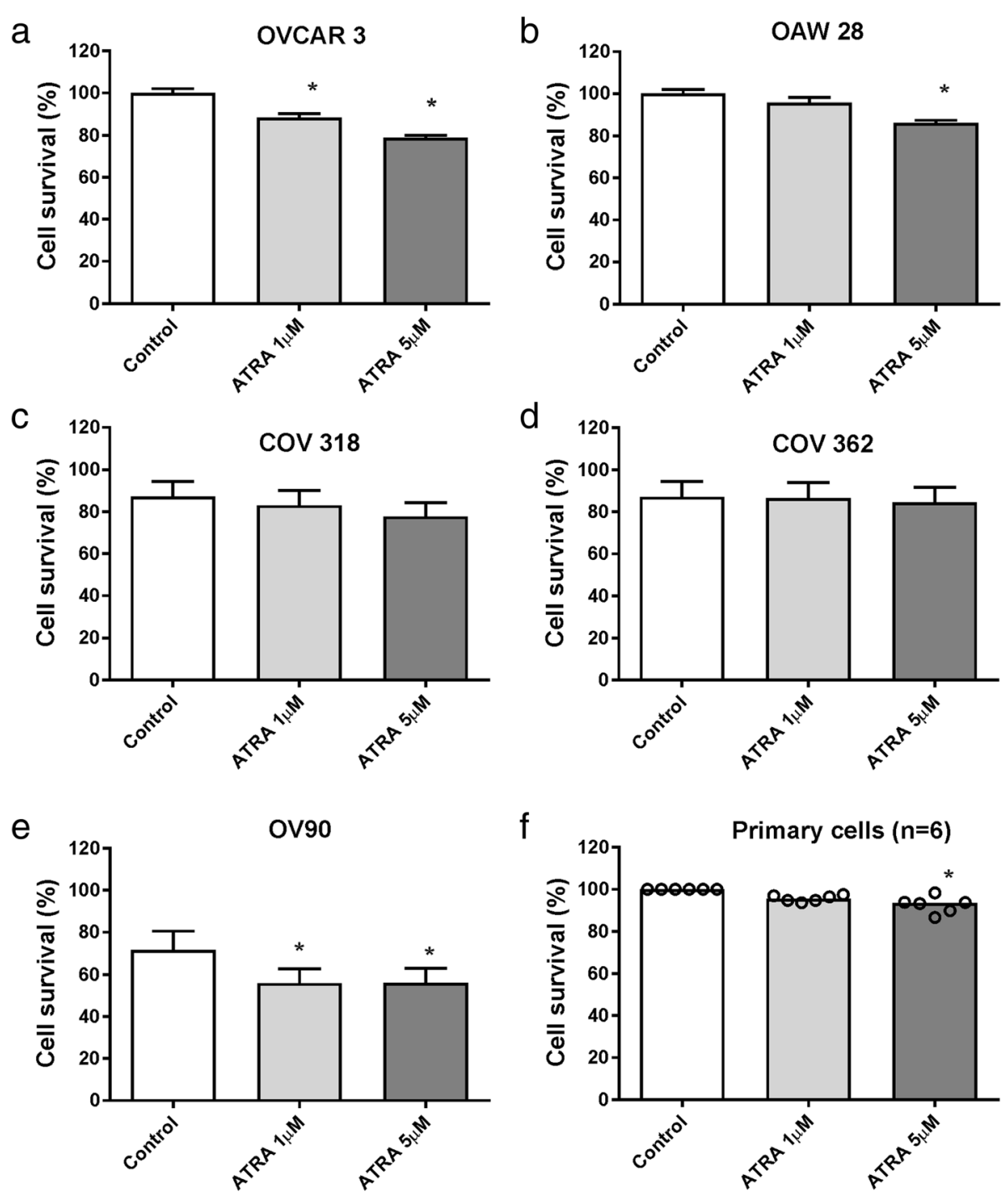

Fig. 1 The effect of ATRA treatment on serous ovarian cancer cell proliferation. Cell survival in response to 6 days ATRA treatment $(1,5 \mu M)$ is shown in order of cell invasiveness a OVCAR-3, b OAW28, c COV-318, d COV- 362, e OV-90 and primary serous ovarian cancer cells ( $n=6$ ) (f). Data are expressed as percentage of control, mean \pm SEM from 3 to 4 independent experiments (20-24 determinations) in (a-e) and quadruplicate determinations for primary cells from 6 individual patients in (f). Statistical significance for a-e was determined using one-way ANOVA (Tukey multiple comparison post hoc test) and the paired Friedman test (Dunn's multiple comparison test) for (f), ${ }^{*} p<0.05$

Effect of ATRA treatment on plasmin generation, ovarian cancer cell motility and invasion

ATRA ( 1 and $5 \mu \mathrm{M})$ treatment significantly inhibited plasmin generation in OAW28 ( $\sim 45 \%$ of control, Fig. $2 \mathrm{a})$ but did not significantly affect plasmin activation in OV90 cells (Fig. 2b). ATRA treatment also had no significant effect on plasmin activation in OVCAR-3 cells (Fig. 2c). However in the presence of plasmin inhibitor, $\varepsilon$-ACA, plasmin generation was significantly inhibited in OAW28, OV-90 and OVCAR-3 cells (Fig. 2a-c). We next examined the effects of ATRA on motility and invasion of OAW28 and OV-90. Both OAW28 motility (Fig. 3a, $p<0.0001$ ) and invasion (Fig. 3a, $p=0.0008$ ) were inhibited by 6 days of ATRA ( 1 and $5 \mu \mathrm{M})$ treatment. Invasion but not motility of OV-90 cells was significantly inhibited by 6 days of ATRA ( 1 and $5 \mu \mathrm{M})$ treatment (Fig. 3b, $p=0.0073$ ).

\section{Effects of ATRA on annexin A2 and S100A10 expression} in serous ovarian cancer cell lines

We examined the effects on ATRA treatment on the expression of both ANXA2 and S100A10 in OAW28 and OV-90 cells by qRT-PCR. No significant effect on ANXA2 expression was observed in OAW28 or OV-90 cell lines (Fig. 4a and b) following 1-6 days of ATRA $(1 \mu \mathrm{M}$ or $5 \mu \mathrm{M})$ treatment. However, ATRA treatment 

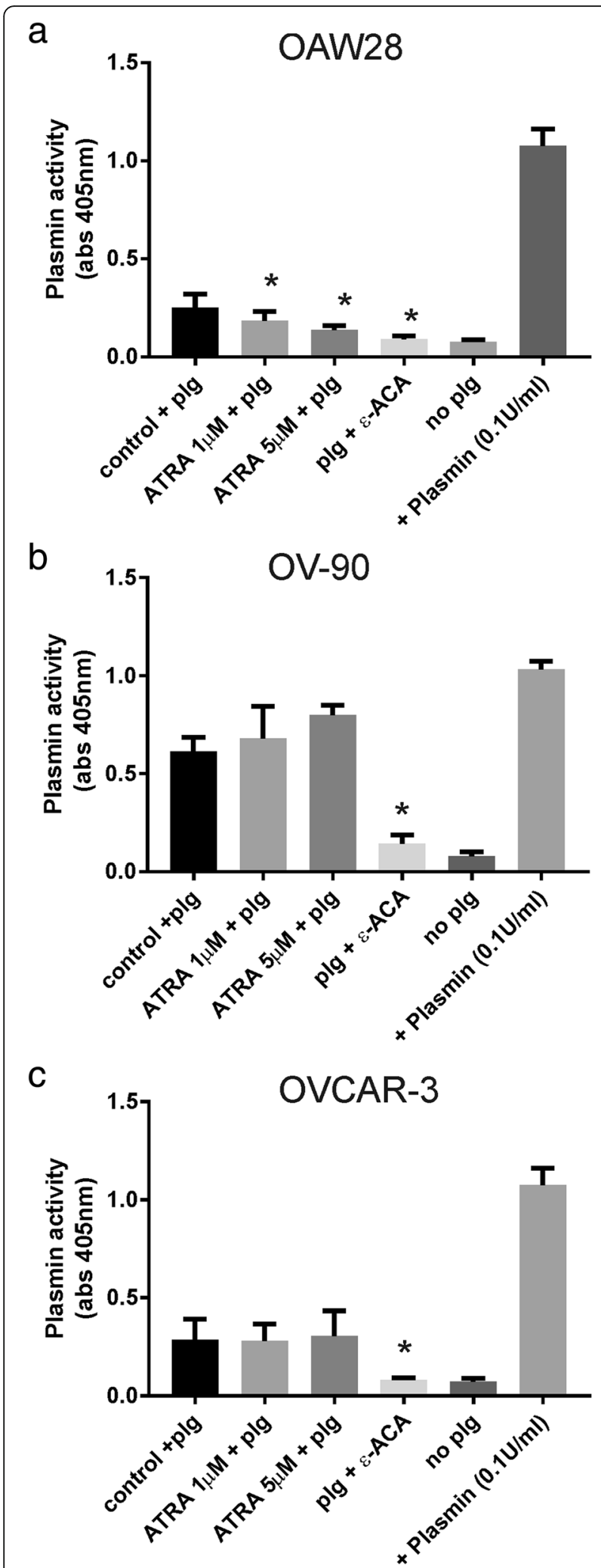

Fig. 2 The effect of ATRA treatment on plasmin generation. Effect of 6 days ATRA treatment $(5 \mu \mathrm{M})$ on plasmin activation in OAW28 (a), OV-90 (b), and OVCAR-3 (c) cells. Plg = plasminogen, $\varepsilon-A C A=\varepsilon-$ aminocaproic acid. Data are the absorbance readings at $405 \mathrm{~nm}$ from 2 to 3 independent experiments (4-10 determinations). Statistical significance was determined using one-way ANOVA and the Tukey multiple comparison post hoc test, ${ }^{*} p<0.05$

$(5 \mu \mathrm{M})$ for 6 days significantly reduced the expression of S100A10 in OAW28 (Fig. 4c) but not OV-90 cells (Fig. 4d). We performed western blotting to determine if ATRA had effects on annexin A2 and S100A10 protein levels. An annexin $\mathrm{A} 2$ band at $38 \mathrm{kDa}$ and an 11 $\mathrm{kDa}$ band for S100A10 was observed in both cell lines, respectively (Fig. 4e and f). ATRA treatment reduced annexin A2 protein levels in OAW28 (88\% of control with $5 \mu \mathrm{M}$ ATRA, Fig. 4e) but had a minimal effect on annexin A2 protein levels in OV-90 cells (96\% of control with $5 \mu \mathrm{M}$ ATRA, Fig. 4f). ATRA treatment markedly reduced S100A10 protein levels in OAW28 (57\% of control with $5 \mu \mathrm{M}$ ATRA, Fig. 4e) but had minimal effect on S100A10 protein levels in OV-90 cells (89\% of control with $5 \mu \mathrm{M}$ ATRA, Fig. 4f). ATRA treatment $(5 \mu \mathrm{M})$ significantly reduced the proportion of OAW28 cells exhibiting membrane annexin A2 (Fig. 5a, $p=$ 0.004 ) and S100A10 (Fig. 5b, $p=0.002$ ) but did not significantly affect membrane localization of annexin A2 or S100A10 in OV-90 cells (Fig. 5c and d).

\section{Effect of ATRA treatment using ex vivo serous ovarian cancer tissue explant assay}

The effect of ATRA treatment $(1 \mu \mathrm{M})$ on ex vivo high grade serous ovarian cancer tissues was assessed by immunohistochemistry using antibodies to cleaved caspase 3 (Fig. 6a) and Ki67 (Fig. 6b), respectively. ATRA treatment significantly increased the number of positive cleaved caspase 3 cells (Fig. 6a, $p=0.0024$, Wilcoxon rank test) and significantly reduced Ki67 positivity (Fig. $6 \mathrm{~b}, p=0.0034$, Wilcoxon rank test) in the serous ovarian cancer explant tissues. Effects of ATRA on apoptosis and proliferation were associated with a significant reduction in total S100A10 protein levels by immunohistochemistry (Fig. $7 \mathrm{~b}, p=0.0273$, Wilcoxon rank test). However total annexin A2 protein levels were not altered by ATRA treatment (Fig. 7a, $p=0.156$, Wilcoxon rank test).

\section{Discussion}

ATRA is used clinically to improve bleeding symptoms in patients with APL [20]. There has been great interest in expanding the therapeutic use of ATRA to other cancers due to its low toxicity $[37,38]$. In this study we show that ATRA treatment: 1) inhibited cell survival in 3 serous ovarian cancer cell lines (OVCAR-3, OAW28 

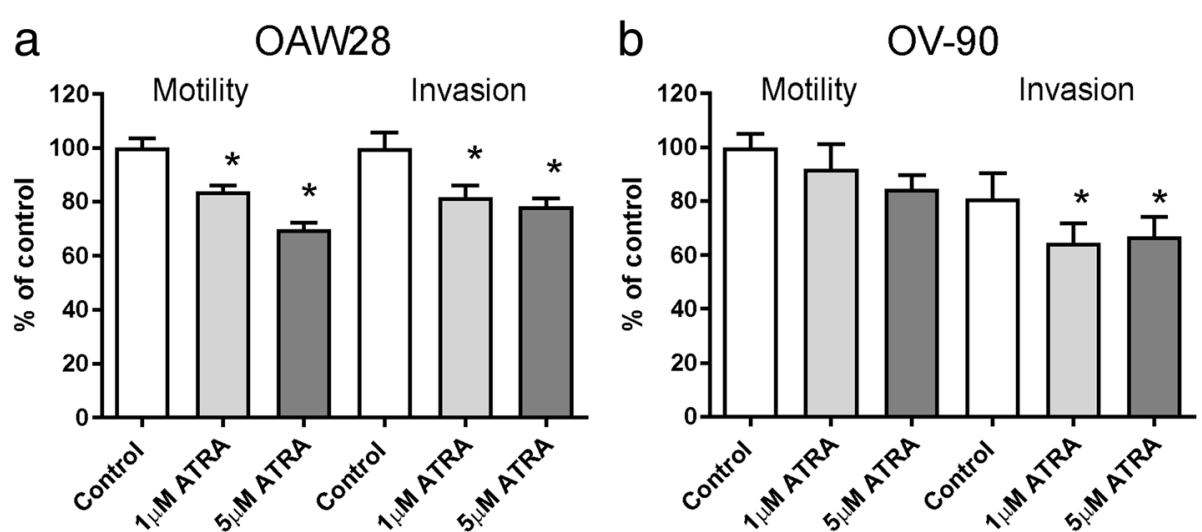

Fig. 3 Effect of ATRA treatment on motility and invasion. Effect of 6 days ATRA treatment $(1,5 \mu \mathrm{M})$ on motility and invasion of OAW28 (a) and OV-90 cells (b). Data are expressed as percentage of DMSO control, mean \pm SEM from 3 to 5 independent experiments (10-20 determinations). Statistical significance was determined using one-way ANOVA and the Tukey multiple comparison post hoc test, ${ }^{*} p<0.05$

\& OV-90), 2) reduced proliferation of primary serous ovarian cancer cells derived from patient ascites, 3) inhibited plasmin production by OAW28 but not OV90 or OVCAR-3 cells, 4) reduced S100A10 expression and membrane localization of both S100A10 and annexin A2 in OAW28 cells but not OV-90 cells, 5) inhibited invasion of both OAW 28 and OV-90 cells, 6) increased apoptosis and decreases proliferation in ex vivo high grade serous ovarian cancer tissues and 7) reduced S100A10 but not annexin A2 protein levels in ex vivo high grade serous ovarian cancer tissues. Together our findings indicate that ATRA has promising potential as a novel therapeutic against high grade serous ovarian cancer.

ATRA was effective at inhibiting cell survival by more than $20 \%$ in 2 of 5 serous ovarian cancer cell lines (OVCAR-3, OV-90) and was very effective at increasing apoptosis and decreasing proliferation in serous ovarian cancer tissues in the ex vivo tissue explant assay. These findings are supported by previous in vitro ovarian cancer studies that have shown ATRA treatment inhibited growth or cell cycle progression of a range of ovarian cancer cell lines including ES2, A2780, CP70, OVCAR-3, MDAH-2774, CAOV3 and HOC-7 [27-31, 39]. Wu et al. (1997) and Soprano et al. (2006) showed that ATRA $\left(10^{-6}\right.$ to $\left.10^{-10} \mathrm{M}\right)$ inhibited cell cycle progression at the G1 stage of the cell cycle in CAOV-3 cells but had no effect on a highly invasive ovarian cancer cell line, SKOV-3 following 7 to 15 days of ATRA treatment [28, 31]. Krupitza et al. (1995) showed effects of ATRA (40 to $140 \mathrm{~nm}$ ) alone induced HOC-7 cell apoptosis and decreased cell viability [29]. Similarly, Karabulut et al. (2010) showed ATRA $(10 \mu \mathrm{M})$ suppressed cell growth and increased cell apoptosis in two ovarian cancer cell lines (OVCAR-3 and MDAH-2774) [27].
A recent study using network guided modelling in more than 30 tumor types identified an ATRA-21 gene signature that has potential to be used to predict response to ATRA in individual patients [26]. The ATRA21 gene signature correctly identified APL as the most sensitive leukaemia subtype to respond to ATRA treatment but also identified patients with high sensitivity prediction scores with many other tumor types that may also benefit from ATRA treatment [26]. Interestingly, up to $29 \%(117 / 402)$ of serous carcinoma patients exhibited a high sensitivity prediction score $(>0.266)$ similar to AML patients [26]. The sensitivity prediction score using the ATRA-21 signature significantly correlated with ATRA response in the Genomic Drug Sensitivity Cancer (GDSC) project. Two of 13 ovarian cancer cell lines (OAW28 and A2780) reached the 20\% reduction in cell number threshold in the GDSC study [26]. Other serous ovarian cancer cell lines investigated in this study including OVCAR-3, COV318, COV362 and OV-90 were not included in both the ATRA 21-prediction modelling and the GDSC project [26].

We found that serous ovarian cancer cells COV362 and COV318 were resistant to ATRA treatment. In previous studies, SKOV-3, and CP70 ovarian cancer cells have also been shown to be resistant to ATRA [28, 39]. Although is not clear why ovarian cancer cell lines are resistant to ATRA treatment, our study suggests that resistance to ATRA treatment is not dependent on RARA, ANXA2 or S100A10 expression as all of the serous ovarian cancer cell lines expressed similar mRNA levels of these genes (Additional file 3: Figure S1a). Moreover, ATRA treatment response is not associated with the invasive potential of serous ovarian cancer cells as the survival of both less invasive (OVCAR-3, OAW28) and the more highly invasive serous ovarian cancer cell line (OV-90) was inhibited by ATRA 
a

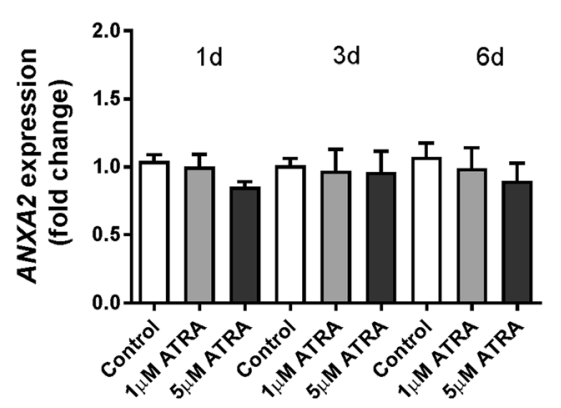

C

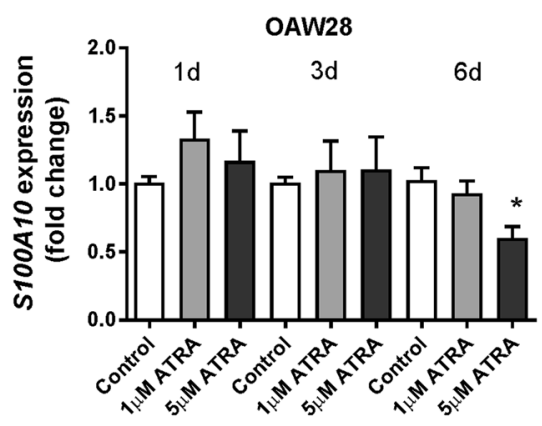

e
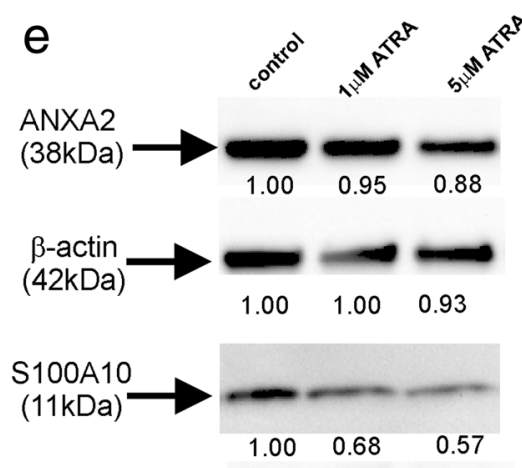

$\beta$-actin

(42kDa)

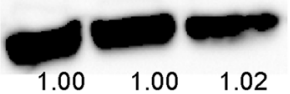

OAW28

b

OV-90

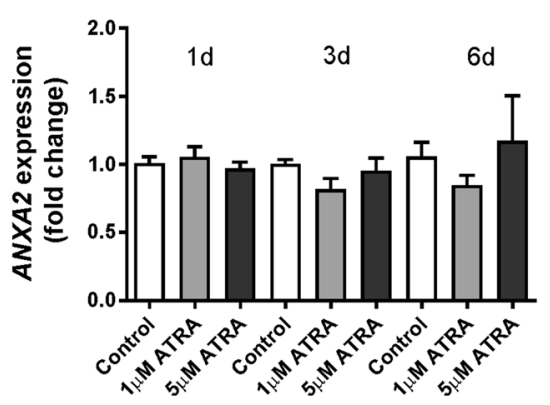

d

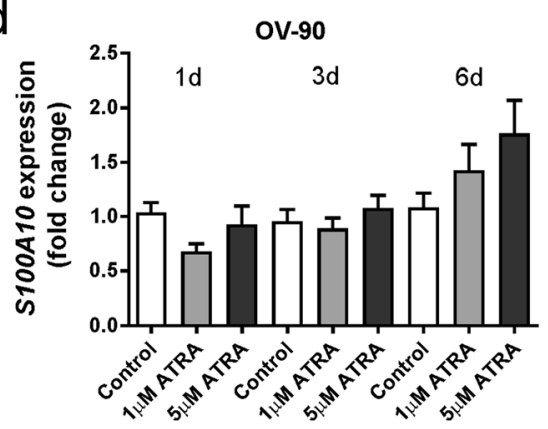

f
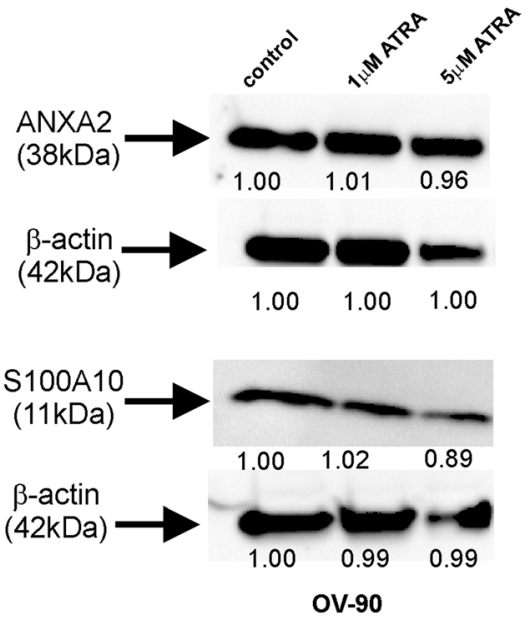

Fig. 4 The effect of ATRA treatment on expression of ANXA2 and S100A10 mRNA and protein levels. The effect on ANXA2 and S100A10 expression

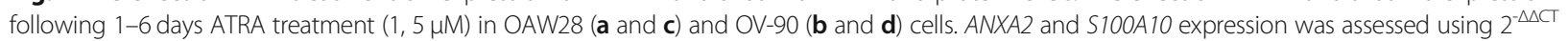
quantitation method and normalised to housekeeping gene $\beta$-actin using no treatment control as a calibrator. Data is from 2 to 4 independent experiments $(n=4-12)$. Statistical significance was determined using one-way ANOVA and the Tukey multiple comparison post hoc test. Western blots for annexin A2 and S100A10 (e and f) following 6 days ATRA treatment (1,5 $5 \mathrm{M}$ ). Annexin A2 bands at $38 \mathrm{kDa}, \mathrm{S} 100 \mathrm{~A} 10$ at 11 $\mathrm{kDa}$ and $\beta$-actin bands at $42 \mathrm{kDa}$ are shown for OAW28 (e) and OV-90 (f) cells. Equal amounts protein (5 $\mu \mathrm{g}$ for annexin A2 \& $15 \mu \mathrm{g}$ S100A10 were run on a 4-12\% SDS-PAGE gel and immunoblotted with mouse monoclonal antibodies to annexin A2 (1/2000, BD Biosciences) or S100A10 (1/2000, BD Biosciences). A rabbit polyclonal antibody was used detect $\beta$-actin (1/2000, ab8227, Abcam). Numbers below western bands in e and $f$ are fold changes relative to the control treatment. Westerns blots are representative of two independent experiments

treatment. A recent study reported that ovarian cancer cell lines with a high ratio of intracellular lipid binding proteins $C R A B P 2 / F A B P 5$, involved in retinoic acid delivery from the cytoplasm to nucleus [36] were growth inhibited by 7 days ATRA $(7 \mu \mathrm{M})$ treatment [40]. Our results demonstrating anti-proliferative effects of ATRA in OAW28 cells which exhibited the highest CRABP2/
FABP5 ratio agree with these findings however, this notion is not supported in OV-90 cells which exhibited the lowest $C R A B P 2 / F A B P 5$ ratio. The response to ATRA treatment in OV-90 cells may be dependent on the expression of other signaling pathways. Wu et al. (1997) suggested that ATRA blocks the cell cycle progression in G1 stage in CAOV3 cells and targets a downstream 


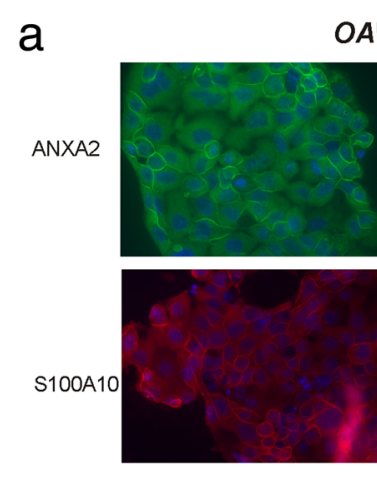

DMSO

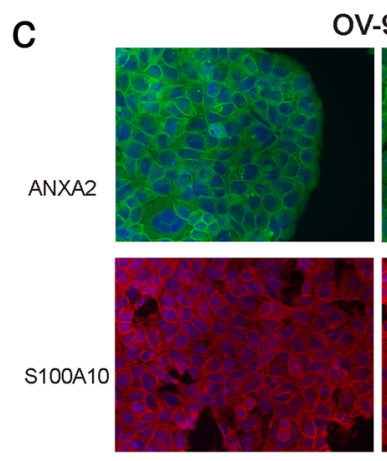

DMSO

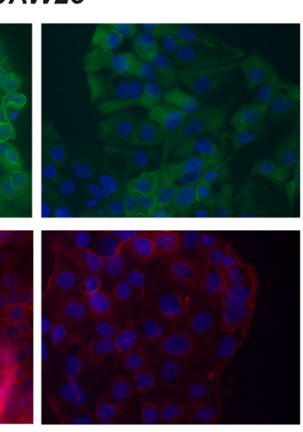

ATRA

OV-90
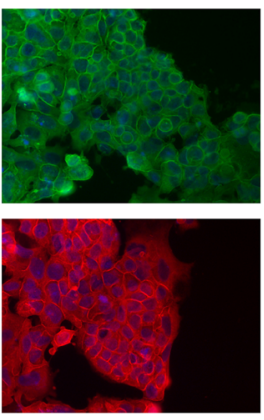

ATRA b

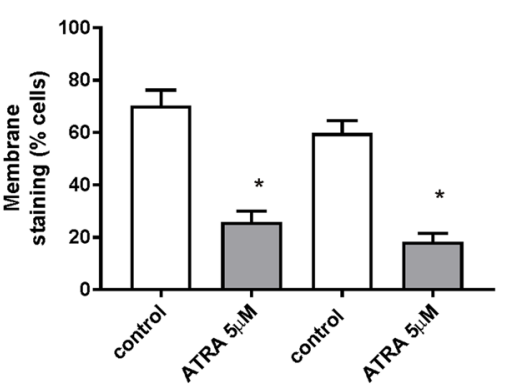

ANXA2

d

OV-90

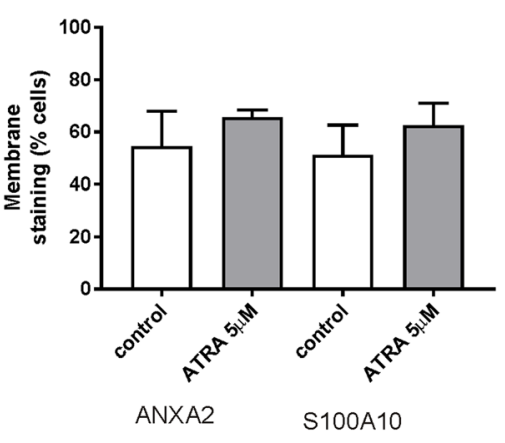

Fig. 5 Effect of ATRA treatment on membrane localization of ANXA2 and S100A10 in OAW28 and OV-90 cells. ANXA2 and S100A10 immunofluorescence in OAW28 (a) and OV-90 (c) cells \pm treatment with ATRA (5 $\mu \mathrm{M})$. ANXA2 and S100A10 membrane localization is significantly reduced in OAW28 cells (b) but not OV-90 cells (d) following 6 days ATRA treatment. Data is expressed as mean \% membrane positive cells \pm SEM from 3 independent experiments. ${ }^{*} p<0.05$ (unpaired student $t$ test)

a

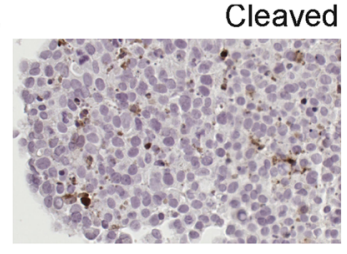

control

b

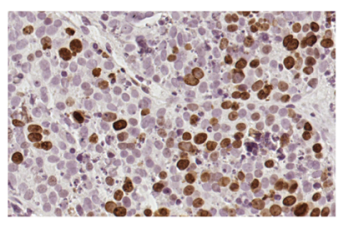

control

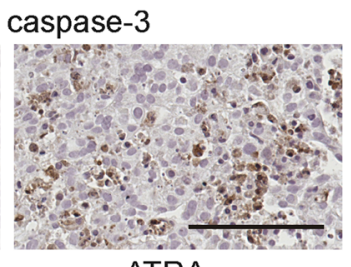

ATRA

Ki67

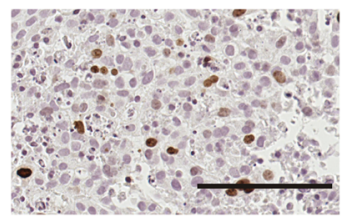

ATRA
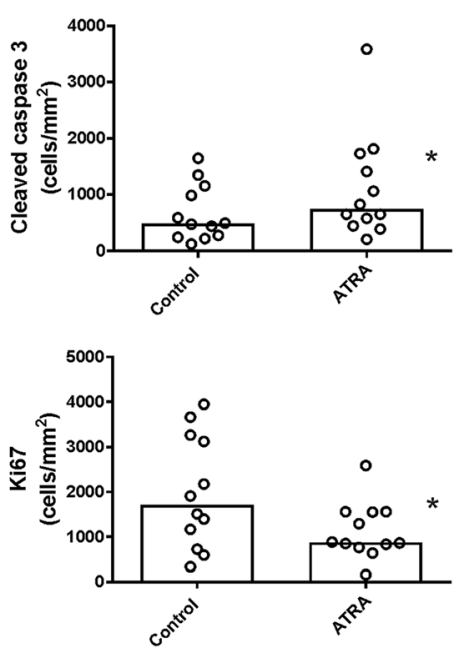

Fig. 6 The effect of ATRA treatment on proliferation and apoptosis in ex vivo tissue explants. High grade serous ovarian cancer tissues ( $n=12$ ) were treated with control medium (0.1\% DMSO) or ATRA $(1 \mu \mathrm{M})$ for $72 \mathrm{~h}$. Apoptosis was assessed using an antibody to cleaved caspase 3 (a) and proliferation was assessed using Ki67 antibody (b). Representative images for cleaved caspase 3 and Ki67 are shown (scale bar $=100 \mu \mathrm{m}$, all images are the same magnification). The summary of the immunostaining quantitation for cleaved caspase 3 (a) and Ki67 (b) is shown. The data represents the number of Ki67 or cleaved caspase 3 positive cells $/ \mathrm{mm}^{2}$ for each tissue. The bar is the median value. ${ }^{*} p<0.05$, Wilcoxon pair test 

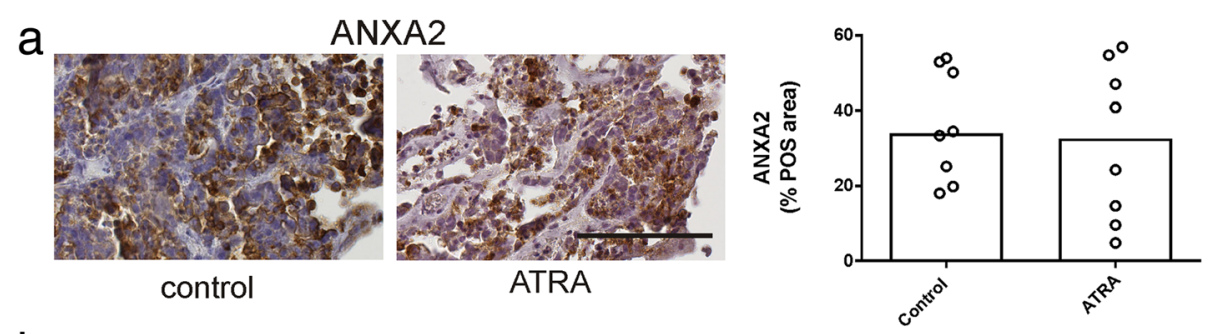

b
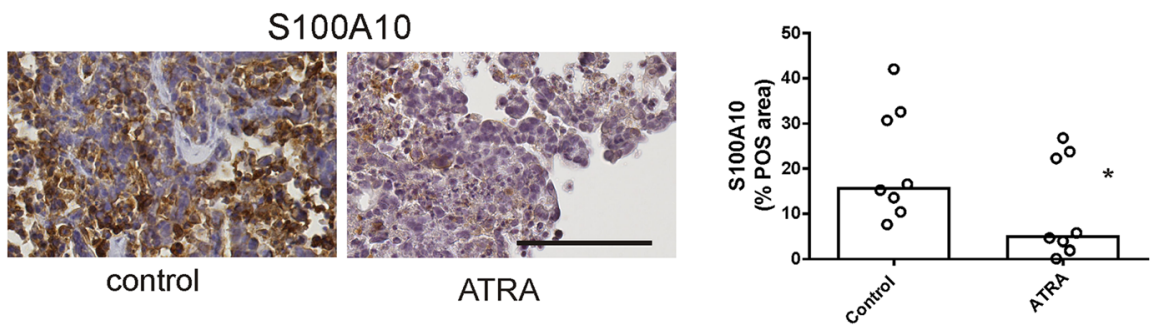

Fig. 7 The effect of ATRA treatment on annexin A2 and S100A10 protein levels in ex vivo tissue explants. High grade serous ovarian cancer tissues were treated with control medium $(0.1 \%$ DMSO) or ATRA $(1 \mu \mathrm{M})$ for $72 \mathrm{~h}(n=8)$. Representative images for annexin A2 (a) and S100A10 (b) immunostaining are shown (scale bar $=100 \mu \mathrm{m}$, all images are the same magnification). The summary of the annexin A2 and S100A10 immunostaining quantitation for 8 patients are shown. The data represents the area of annexin A2 or S100A10 positivity measured by video image analysis (\% positive area). The bar is the median value. ${ }^{*} p<0.05$, Wilcoxon pair test

process or the event occurring at a point after the insulin/IGF-1, oestrogen and serum signal transduction pathways converge [28]. This is supported by Ravikumar et al. (2007) that showed that ATRA $(1 \mu \mathrm{M})$ treatment blocks the IGFR-1 signalling pathway in CAOV3 by inhibiting the expression of insulin receptor substrate-1 (IRS-1) [39].

The resistance to ATRA may also be as a result of poor delivery of ATRA into ovarian cancer cells due to its high lipophilic nature or the length of treatment $[41,42]$. Interestingly, although there were no effects of ATRA treatment on cell proliferation and apoptosis of SKOV-3 cells in previous studies [28, 39], a recent study by Narvekar et al. (2014) showed ATRA's pharmaceutical properties could be enhanced by polymer-oil nanostructured carriers in SKOV-3 cells [41]. Oil-soluble ATRA treatment molecules easily permeate across the cell membrane, induced apoptotic cell death and a long-term anti-tumorigenic effect in SKOV-3 cells [41]. Oil soluble formations of ATRA may improve effectiveness of the delivery of ATRA in ovarian cancer cells and should be further evaluated. More recently Young et al. (2015) showed 3 days treatment with ATRA $(10 \mu \mathrm{M})$ did not affect proliferation of ovarian cancer cell lines (A2780 and CP70) however, a longer ATRA treatment for 28 days was effective at inhibiting A2780 tumour growth in vivo using mouse xenografts [42]. ATRA treatment reduced expression of the stem cell marker, ALDH1 however the study did not examine effects of ATRA on annexin A2 or S100A10 expression [42]. Future studies should also consider longer treatment times to evaluate the effectiveness of ATRA treatment.
ATRA treatment for 6 days treatment significantly reduced the expression of S100A10 but not ANXA2 in OAW28. Similarly, S100A10 but not annexin A2 protein levels were reduced by ATRA treatment in OAW28 cells. We also found that ATRA treatment significantly reduced S100A10 but not ANXA2 protein levels in the ex vivo explant assay. It is likely that reduced S100A10 protein levels inhibit the assembly of annexin A2 heterotetramer (AIIt) in the cell membrane. This view is supported by our findings that both S100A10 and annexin A2 are reduced in cell membranes of OAW28 cells following ATRA treatment. The study by O'Connell et al. (2011) also that showed ATRA treatment $(1 \mu \mathrm{M})$ reduced S100A10 cell surface expression to a greater extent than annexin A2 in leukemia cells [21]. Gladwin et al. (2000) showed that ATRA $\left(10^{-5}\right.$ to $\left.10^{-9} \mathrm{M}\right)$ treatment for 6-8 days reduced S100A10 protein levels but not S100A10 mRNA levels in bronchial epithelial cells (BEAS-2B), suggesting the involvement of a post-translational mechanism [43]. A recent study investigated the mechanism whereby ATRA regulates cell surface expression of S100A10 in APL leukemic cells [44]. They found evidence that ATRA can reduce S100A10 protein levels via an ubiquitin-independent manner [44]. Furthermore they also reported that ATRA treatment reduced S100A10 expression but not ANXA2 mRNA or protein levels in the MCF-7 breast cancer cells [44]. The study concluded that ATRA can regulate S100A10 levels independently of PML/RAR $\alpha$ and annexin A2 [44]. Our findings support these observations and suggest that ATRA acts 
predominately on S100A10 in the plasminogen activation pathway in serous ovarian cancer cells.

The invasion of both OAW28 and OV-90 cells was inhibited by ATRA treatment. This findings concur with Young et al. (2015) that showed that ATRA $(10 \mu \mathrm{M})$ treatment for 28 days inhibited cell migration and invasion of two ovarian cancer cell lines (A2780 and CP70) [42]. ATRA treatment has also recently been shown to inhibit the motility and EMT phenotype of SKBR3 breast cancer cells [45]. Interestingly, ATRA inhibited OV-90 cell survival and invasion but did not affect annexin A2 or S100A10 expression or plasmin generation in these cells, whilst ATRA effects on cell survival and motility and invasion were associated with effects on S100A10 expression and plasmin activation in OAW28 cells. Our findings suggest that ATRA acts predominately to reduce S100A10 protein levels and plasmin production in OAW28 cells, however ATRA effects in OV-90 cells appear to be independent of its effects on the plasminogen activation pathway. It is likely that ATRA acts via an alternative pathway in OV-90 cells, and requires further investigation.

\section{Conclusion}

In conclusion, ATRA has anti-tumor activity on serous ovarian cancer cell lines in vitro and significantly decreased proliferation and increased apoptosis in ex vivo high grade serous ovarian cancer tissues. ATRA has promising potential as a novel therapy against ovarian cancer and should be further evaluated.

\section{Additional files}

Additional file 1: Summary of clinicopathological characteristics of ovarian cancer patients used to isolate primary ovarian cancer cells from ascites. (DOCX $14 \mathrm{~kb}$ )

Additional file 2: Summary of clinicopathological characteristics of ovarian cancer patients used in the ex vivo explant assay. (DOCX $18 \mathrm{~kb}$ )

Additional file 3: Gene expression in serous ovarian cancer cell lines. a) Gene expression data for ovarian cancer cell lines obtained from Cancer Cell Line Encyclopaedia. https://portals.broadinstitute.org/ccle. b) Relationship between ATRA response (\% cell survival) and CRABP2/FABP5 ratio in serous ovarian cancer cell lines. (TIF 96 kb)

\section{Abbreviations}

APL: Acute promyelocytic leukemia; ATRA: All trans retinoic acid; CM: Conditioned media; CT: Cycle threshold; DMSO: Dimethyl sulfoxide; EMT: Epithelial to mesenchymal transition; FCS: Fetal calf serum; GDSC: Genomic Drug sensitivity Cancer; IGFR-1: Insulin growth factor receptor 1; IRS-1: Insulin receptor substrate-1; MMP: Matrix metalloproteinase; MTT: 3-(4,5-dimethylthiazol-2-yl)-2,5-diphenyltetrazolium bromide; PBS: Phosphate buffered saline; PCR: Polymerase chain reaction; Plg: Plasminogen; RARA: Retinoic acid receptor alpha gene; STR: Short tandem repeat; tPA: Tissue plasminogen activator; $\varepsilon$-ACA: $\varepsilon$-aminocaproic acid

\section{Acknowledgments}

We thank the following students: Ms. Wanqi Wang and Ms. Christine Gan for their help with the immunostaining and scoring of the explant tissues.

\section{Funding}

This research has been funded by the Ovarian Cancer Research Foundation (OCRF), Australia. CR is currently supported by the Lin Huddleston Ovarian Cancer Fellowship funded by the Cancer Council South Australia and the Adelaide Medical School, University of Adelaide.

\section{Availability of data and materials}

Data sharing not applicable to this article as no datasets were generated or analysed during the current study.

\section{Authors' contributions}

$\mathrm{RH}, \mathrm{NAL}$ and $\mathrm{CR}$ performed the experiments, analysed and interpreted the data and contributed to drafting the manuscript. $\mathrm{RH}, \mathrm{KG}$ and WMB performed the immunohistochemistry. $\mathrm{CR}, \mathrm{KG}$ and $\mathrm{RH}$ performed the histological assessment Ki67 and cleaved caspase 3. CR and MKO conceived the study and participated in the design and coordination and helped draft the manuscript. All authors read and approved the final manuscript.

\section{Ethics approval and consent to participate}

Ovarian cancer tissues was obtained with informed patient consent and approval of the Royal Adelaide Hospital Human Ethics Committee. Primary ovarian cancer cells were derived from ascites collected from advanced stage serous ovarian cancer patients after informed consent and with approval from the Royal Adelaide Hospital Human Ethics Committee.

\section{Consent for publication}

Not applicable.

\section{Competing interests}

The authors declare that they have no competing interests.

\section{Publisher's Note}

Springer Nature remains neutral with regard to jurisdictional claims in published maps and institutional affiliations.

\section{Author details}

${ }^{1}$ Discipline of Obstetrics and Gynaecology, Adelaide Medical School, Robinson Research Institute, University of Adelaide, Adelaide, South Australia 5000, Australia. ${ }^{2}$ Department of Gynaecological Oncology, Royal Adelaide Hospital, Adelaide, South Australia 5005, Australia.

Received: 15 August 2018 Accepted: 19 December 2018 Published online: 08 January 2019

\section{References}

1. Torre LA, Bray F, Siegel RL, Ferlay J, Lortet-Tieulent J, Jemal A. Global cancer statistics, 2012. CA Cancer J Clin. 2015;65(2):87-108.

2. Siegel RL, Miller KD, Jemal A. Cancer statistics, 2017. CA Cancer J Clin. 2017; 67(1):7-30.

3. Saad AF, Hu W, Sood AK. Microenvironment and pathogenesis of epithelial ovarian cancer. Horm Cancer. 2010;1(6):277-90.

4. Correia AL, Bissell MJ. The tumor microenvironment is a dominant force in multidrug resistance. Drug Resist Updat. 2012;15(1-2):39-49.

5. Nik NN, Vang R, Shih le M, Kurman RJ. Origin and pathogenesis of pelvic (ovarian, tubal, and primary peritoneal) serous carcinoma. Annu Rev Pathol. 2014;9:27-45.

6. Ween MP, Lokman NA, Hoffmann P, Rodgers RJ, Ricciardelli C, Oehler MK. Transforming growth factor-beta-induced protein secreted by peritoneal cells increases the metastatic potential of ovarian cancer cells. Int J Cancer. 2011;128(7):1570-84.

7. Lokman NA, Ween MP, Oehler MK, Ricciardelli C. The role of annexin A2 in tumorigenesis and cancer progression. Cancer Microenviron. 2011; 4(2):199-208.

8. Lokman NA, Elder AS, Ween MP, Pyragius CE, Hoffmann P, Oehler MK, et al. Annexin A2 is regulated by ovarian cancer-peritoneal cell interactions and promotes metastasis. Oncotarget. 2013;4(8):1199-211.

9. Lokman NA, Pyragius CE, Ruszkiewicz A, Oehler MK, Ricciardelli C. Annexin A2 and S100A10 are independent predictors of serous ovarian cancer outcome. Transl Res. 2016;171:83-95.e1-2.

10. Bharadwaj A, Bydoun M, Holloway R, Waisman D. Annexin A2 heterotetramer: structure and function. Int J Mol Sci. 2013;14(3):6259-305. 
11. Waisman DM. Annexin II tetramer: structure and function. Mol Cell Biochem. 1995;149-150:301-22.

12. Hedhli N, Falcone DJ, Huang B, Cesarman-Maus G, Kraemer R, Zhai H, et al. The annexin A2/S100A10 system in health and disease: emerging paradigms. J Biomed Biotechnol. 2012;2012:406273.

13. Myrvang HK, Guo X, Li C, Dekker LV. Protein interactions between surface annexin A2 and S100A10 mediate adhesion of breast cancer cells to microvascular endothelial cells. FEBS Lett. 2013;587(19):3210-5.

14. Bydoun M, Waisman DM. On the contribution of S100A10 and annexin A2 to plasminogen activation and oncogenesis: an enduring ambiguity. Future Oncol. 2014;10(15):2469-79.

15. Diaz VM, Hurtado M, Thomson TM, Reventos J, Paciucci R. Specific interaction of tissue-type plasminogen activator (t-PA) with annexin II on the membrane of pancreatic cancer cells activates plasminogen and promotes invasion in vitro. Gut. 2004;53(7):993-1000.

16. Sharma M, Ownbey RT, Sharma MC. Breast cancer cell surface annexin II induces cell migration and neoangiogenesis via tPA dependent plasmin generation. Exp Mol Pathol. 2010;88(2):278-86.

17. Degos $\mathrm{L}$, Wang ZY. All trans retinoic acid in acute promyelocytic leukemia. Oncogene. 2001;20(49):7140-5.

18. Menell JS, Cesarman GM, Jacovina AT, McLaughlin MA, Lev EA, Hajjar KA Annexin II and bleeding in acute promyelocytic leukemia. N Engl J Med. 1999:340(13):994-1004.

19. Tang XH, Gudas LJ. Retinoids, retinoic acid receptors, and cancer. Annu Rev Pathol. 2011;6:345-64

20. Lo-Coco F, Avvisati G, Vignetti M, Thiede C, Orlando SM, lacobelli S, et al. Retinoic acid and arsenic trioxide for acute promyelocytic leukemia. N Engl J Med. 2013;369(2):111-21.

21. O'Connell PA, Madureira PA, Berman JN, Liwski RS, Waisman DM. Regulation of S100A10 by the PML-RAR-alpha oncoprotein. Blood. 2011;117(15):4095-105.

22. Olwill SA, McGlynn H, Gilmore WS, Alexander HD. All-trans retinoic acidinduced downregulation of annexin II expression in myeloid leukaemia cell lines is not confined to acute promyelocytic leukaemia. Br J Haematol. 2005; 131(2):258-64.

23. Zhang X, Zhou H, Wang J, Yang L, Hu Y, Shen G, et al. Arsenic trioxide, retinoic acid and Ara-c regulated the expression of annexin II on the surface of APL cells, a novel co-receptor for plasminogen/tissue plasminogen activator. Thromb Res. 2002;106(1):63-70.

24. Garattini E, Bolis M, Garattini SK, Fratelli M, Centritto F, Paroni G, et al. Retinoids and breast cancer: from basic studies to the clinic and back again Cancer Treat Rev. 2014:40(6):739-49.

25. di Masi A, Leboffe L, De Marinis E, Pagano F, Cicconi L, Rochette-Egly C, et al. Retinoic acid receptors: from molecular mechanisms to cancer therapy. Mol Asp Med. 2015:41:1-115.

26. Bolis M, Garattini E, Paroni G, Zanetti A, Kurosaki M, Castrignano T, et al. Network-guided modeling allows tumor-type independent prediction of sensitivity to all-trans-retinoic acid. Ann Oncol. 2017;28(3):611-21.

27. Krupitza G, Hulla W, Harant H, Dittrich E, Kallay E, Huber H, et al. Retinoic acid induced death of ovarian carcinoma cells correlates with c-myc stimulation. Int J Cancer. 1995;61(5):649-57.

28. Wu S, Donigan A, Platsoucas CD, Jung W, Soprano DR, Soprano KJ. All-trans-retinoic acid blocks cell cycle progression of human ovarian adenocarcinoma cells at late G1. Exp Cell Res. 1997;232(2):277-86.

29. Karabulut B, Karaca B, Varol U, Muslu U, Cakar B, Atmaca H, et al. Enhancing cytotoxic and apoptotic effect in OVCAR-3 and MDAH-2774 cells with alltrans retinoic acid and zoledronic acid: a paradigm of synergistic molecular targeting treatment for ovarian cancer. J Exp Clin Cancer Res. 2010;29:102.

30. Purev E, Soprano DR, Soprano KJ. PP2A interaction with Rb2/p130 mediates translocation of Rb2/p130 into the nucleus in all-trans retinoic acid-treated ovarian carcinoma cells. J Cell Physiol. 2011;226(4):1027-34.

31. Soprano KJ, Purev E, Vuocolo S, Soprano DR. Rb2/p130 and protein phosphatase 2A: key mediators of ovarian carcinoma cell growth suppression by alltrans retinoic acid. Oncogene. 2006;25(38):5315-25.

32. Ricciardelli $C$, Lokman NA, Cheruvu S, Tan IA, Ween MP, Pyragius CE, et al. Transketolase is upregulated in metastatic peritoneal implants and promotes ovarian cancer cell proliferation. Clin Exp Metastasis. 2015; 32(5):441-55.

33. Ricciardelli C, Ween MP, Lokman NA, Tan IA, Pyragius CE, Oehler MK. Chemotherapy-induced hyaluronan production: a novel chemoresistance mechanism in ovarian cancer. BMC Cancer. 2013;13:476.
34. Ricciardelli C, Lokman NA, Sabit I, Gunasegaran K, Bonner WM, Pyragius CE, et al. Novel ex vivo ovarian cancer tissue explant assay for prediction of chemosensitivity and response to novel therapeutics. Cancer Lett. 2018:421:51-8.

35. Bianco-Miotto T, Chiam K, Buchanan G, Jindal S, Day TK, Thomas M, et al. Global levels of specific histone modifications and an epigenetic gene signature predict prostate cancer progression and development. Cancer Epidemiol Biomark Prev. 2010;19(10):2611-22.

36. Schug TT, Berry DC, Shaw NS, Travis SN, Noy N. Opposing effects of retinoic acid on cell growth result from alternate activation of two different nuclear receptors. Cell. 2007;129(4):723-33.

37. Schenk T, Stengel S, Zelent A. Unlocking the potential of retinoic acid in anticancer therapy. Br J Cancer. 2014;111(11):2039-45.

38. Centritto F, Paroni G, Bolis M, Garattini SK, Kurosaki M, Barzago MM, et al. Cellular and molecular determinants of all-trans retinoic acid sensitivity in breast cancer: luminal phenotype and RARalpha expression. EMBO Mol Med. 2015;7(7):950-72.

39. Ravikumar S, Perez-Liz G, Del Vale L, Soprano DR, Soprano KJ. Insulin receptor substrate-1 is an important mediator of ovarian cancer cell growth suppression by all-trans retinoic acid. Cancer Res. 2007;67(19):9266-75.

40. Coscia F, Watters KM, Curtis M, Eckert MA, Chiang CY, Tyanova S, et al. Integrative proteomic profiling of ovarian cancer cell lines reveals precursor cell associated proteins and functional status. Nat Commun. 2016;7:12645.

41. Narvekar M, Xue HY, Tran NT, Mikhael M, Wong HL. A new nanostructured carrier design including oil to enhance the pharmaceutical properties of retinoid therapy and its therapeutic effects on chemo-resistant ovarian cancer. Eur J Pharm Biopharm. 2014;88(1):226-37.

42. Young MJ, Wu YH, Chiu WT, Weng TY, Huang YF, Chou CY. All-trans retinoic acid downregulates ALDH1-mediated stemness and inhibits tumour formation in ovarian cancer cells. Carcinogenesis. 2015;36(4):498-507.

43. Gladwin MT, Yao XL, Cowan M, Huang XL, Schneider R, Grant LR, et al. Retinoic acid reduces 111 protein levels in bronchial epithelial cells by a posttranslational mechanism. Am J Physiol Lung Cell Mol Physiol. 2000; 279(6):L1103-9.

44. Holloway RW, Thomas ML, Cohen AM, Bharadwaj AG, Rahman M, Marcato $P$, et al. Regulation of cell surface protease receptor S100A10 by retinoic acid therapy in acute promyelocytic leukemia (APL)(). Cell Death Dis. 2018; 9(9):920.

45. Zanetti A, Affatato R, Centritto F, Fratelli M, Kurosaki M, Barzago MM, et al. All-trans-retinoic acid modulates the plasticity and inhibits the motility of breast Cancer cells: ROLE OF NOTCH1 AND TRANSFORMING GROWTH FACTOR (TGFbeta). J Biol Chem. 2015;290(29):17690-709.

\section{Ready to submit your research? Choose BMC and benefit from:}

- fast, convenient online submission

- thorough peer review by experienced researchers in your field

- rapid publication on acceptance

- support for research data, including large and complex data types

- gold Open Access which fosters wider collaboration and increased citations

- maximum visibility for your research: over $100 \mathrm{M}$ website views per year

At BMC, research is always in progress.

Learn more biomedcentral.com/submissions 